\title{
Tipping Points - Do the Prognostic Values of Multimorbidity and Functional Status Vary with Age?
}

\author{
Lau Caspar Thygesen (1D) \\ Kaare Christensen $\mathbb{D}^{2}$ \\ Mikael Rørth ${ }^{3,4}$ \\ Henrik Toft Sørensen (iD) 3,4 \\ Jan $P$ Vandenbroucke $3,5,6$ \\ Rudi GJ Westendorp (1D)
}

\begin{abstract}
'National Institute of Public Health, University of Southern Denmark, Copenhagen, Denmark; ${ }^{2}$ The Danish Aging Research Center, Department of Public Health, University of Southern Denmark, Odense, Denmark; ${ }^{3}$ Department of Clinical Epidemiology, Aarhus University, Aarhus, Denmark; ${ }^{4}$ Aarhus University Hospital, Aarhus, Denmark; ${ }^{5}$ Department of Medical Statistics and Non-communicable Disease Epidemiology, London School of Hygiene and Tropical Medicine, London, UK; ${ }^{6}$ Department of Clinical Epidemiology, Leiden University Medical Center, Leiden, the Netherlands; ${ }^{7}$ Department of Public Health and Center for Healthy Aging, University of Copenhagen, Copenhagen, Denmark
\end{abstract}

Correspondence: Lau Caspar Thygesen National Institute of Public Health, University of Southern Denmark, Studiestræde 6, Copenhagen, DK-I455, Denmark

Tel +45 655077 7l

Email Ict@sdu.dk

\begin{abstract}
Aging of the population is a pressing challenge for healthcare systems and knowledge of a patient's prognosis is a key to shaping effective interventions. As the prevalence of multimorbidity strongly increases with age, the prognostic value of multiple disease diagnoses for survival among older people may diminish, whereas other measures of health, such as functional status (defined as a measure of an individual's ability to perform activities of daily living), may become more important. In this commentary, the impact of age on the prognostic value of multimorbidity is discussed, with the aim of identifying relevant alternative risk indicators for different age groups. The key question is to determine at what age the prognostic value of multimorbidity for meaningful clinical outcomes decreases and is overridden by the prognostic value of functional status. This tipping point likely depends on age, calendar time, and birth cohort. The public health and clinical implications of these tipping points are important. Among younger and middle-aged persons, interventions could be directed towards prevention and treatment of specific diseases, while among older persons efforts should focus more on improving functional levels that include physical, emotional, and social dimensions.
\end{abstract}

Keywords: chronic disease, health services, public health, aged, multimorbidity

\section{Introduction}

During the past 200 years, life expectancy has doubled in many European countries, and internationally also in countries like Japan and Australia. ${ }^{1}$ This leads to an increasing demand for available resources since old people have higher healthcare utilizations, and is therefore a pressing challenge for current healthcare systems. ${ }^{2-4}$ Diagnostics, treatment, and management of age-related non-communicable diseases have greatly improved and the threshold for initiating preventive treatment of asymptomatic conditions has been lowered. ${ }^{5}$ Consequently, the number of patients with several coexisting diseases or conditions, that is multimorbidity, ${ }^{6,7}$ has increased dramatically. Patients with these conditions are living longer and seeing multiple healthcare providers. Multimorbidity is associated with poorer quality of life, ${ }^{8,9}$ more complex and fragmented clinical care, ${ }^{10,11}$ and adverse health outcomes. The result is increased numbers of healthcare contacts, longer hospital admissions, and increased mortality risk. ${ }^{12,13}$ Clinical care will remain suboptimal if the focus remains on handling individual, specific diseases.

The prevalence of multimorbidity increases markedly with age. The estimated prevalence ranges from $55 \%$ to $98 \%$ among persons older than 60 , and is highly dependent on the definition of "old" as well as on the applied diagnostic criteria and data collection methods. ${ }^{8,14,15}$ Studies have shown that the prevalence of 
multimorbidity has increased over calendar time, probably because of increased diagnostic scrutiny and improved survival after initial diagnosis. ${ }^{16,17}$ Due to this high prevalence, and the ambiguity of disease diagnoses, multimorbidity may no longer have the same prognostic value in relation to detrimental outcomes.

In the current situation, in which multimorbidity is increasing with age and over calendar time, the importance of multimorbidity, in the sense of 'having many diagnoses', as a risk indicator of clinical meaningful outcomes (for example mortality) may diminish. Instead, other measures of health, in particular functional status, may be more important among older persons and may also change over calendar time. ${ }^{18-21}$ Functional status includes mobility, strength, and cognition that may influence a person's ability to perform everyday tasks.

In this paper, we discuss the impact of age on the prognostic value of multimorbidity, with the aim of identifying relevant alternative risk indicators for different age groups.

\section{Influence of Age on the Prognostic Value of Multimorbidity and Functional Status}

Like multimorbidity, the prevalence of poor functional status including disability or frailty is also strongly agedependent. ${ }^{19-21}$ This raises the question whether multimorbidity and poor functional status are different clinical phenomena. One could separate these clinical descriptions from the aging processes or, alternatively, argue that they are tightly related with aging. ${ }^{21}$ A key process in aging is the accumulation of permanent damage to somatic cells, leading to cellular dysfunction, and culminating in organ dysfunction and increased risk of dying. ${ }^{22}$ The classic epidemiologic description of multiple age-related pathologies, leading to impairments, functional limitations, and disability, is consistent with this biological definition of aging. ${ }^{23}$ Moreover, the clinical definition of frailty as a decrease in an individual's homeostatic reserve leading to enhanced vulnerability to stressors, adverse disease outcomes, and death, is also related to the biological and epidemiological definition of aging. ${ }^{18}$ As the aging processes affect multiple interrelated physiological systems, the gradual accumulation of defects can explain the agerelated increase in multimorbidity and poor functional status. ${ }^{24}$ Therefore, the aging processes should not be separated from disease processes causing multimorbidity and poor functional status later in life, regardless of whether aging is considered normal or pathological. ${ }^{25}$

Earlier systematic reviews have addressed the overlap between multimorbidity and frailty, reporting a prevalence of multimorbidity in frail individuals of approximately $72 \%$, while the prevalence of frailty among persons with multimorbidity was $16 \%$, confirming that frailty and multimorbidity are associated conditions. ${ }^{26}$ Since only a small proportion of persons with multimorbidity appears to be severely frail, this poses the question whether multimorbidity and frailty should be considered as one entity or as two independent risk indicators. Among communitydwelling older persons of different ages, both risk indicators improved mortality prediction based solely on age and sex - the added value, however, being limited. ${ }^{20}$ Also, the added value of multimorbidity, poor functional level, and subjective health to mortality predictions decreases with increasing age. ${ }^{21}$

Although chronological age strongly predicts mortality, it is a "brute number" that does not use the added insight of differences in functional status in people of the same age. Just as fitness is a marker of good outcomes among young people, mortality risk at age 53 has been found to be lower among those with better grip strength, higher chair rise speed, and longer standing balance time. ${ }^{19}$ In the same vein, physical and cognitive performance, disabilities, and self-rated health have prognostic value for mortality among adults aged 92 years. ${ }^{27}$ These age-based comparisons show that besides the increase in mortality risk during the life course, functional status also predicts outcome.

Among people aged 40-65 years, multimorbidity is often simply defined based on a list and numbers of disease diagnoses, ${ }^{28-30}$ alternatively on drug redemptions. ${ }^{29}$ The rationale is that persons do usually not suffer from major diseases at an earlier age; so, the occurrence of more than one disease has high prognostic value in relation to adverse health outcomes. Hence, summary morbidity scores have high prognostic value and discriminatory power within this age group. ${ }^{30}$

Among the oldest old, eg above the age of 85 years, multimorbidity defined as the number of chronic diseases has lower prognostic value of adverse outcomes, because it strongly depends on the thoroughness of the diagnostic workup. ${ }^{31}$ Depending on the diligence by which diseases are searched for, pre- or subclinical manifestations of different conditions may be present and will determine whether a disease will be diagnosed and/or treated. In a Danish follow-up study of the 1905 and 1915 birth cohorts, the use of 
prescription drugs during the final years of life clearly differed, illustrating that clinical workup and therapy among older people has a secular trend. ${ }^{32}$ For all these reasons, the number of chronic diseases diagnosed loses its discriminatory power whereas measures of physical, cognitive, or social functional levels become more relevant. Functional status is a strong predictor for survival and may be used to make clinical decisions. ${ }^{33}$ In some medical specialties, functional status (eg Karnofsky's performance status) is used routinely to evaluate whether patients are candidates for rigorous clinical interventions. ${ }^{34}$

Another dimension is the relation of multimorbidity and functional level with self-reported health measures. One study found that among people aged 60-77 years, multimorbidity was to a larger degree than functional status associated with low self-rated health, while among older people (78+ years) functional status (measured as walking pace) had higher discriminatory power than multimorbidity, ${ }^{35}$ in line with the reasoning on the prediction of outcomes.

\section{The Influence of Calendar Time on the Prognostic Value of Multimorbidity and Functional Status}

The accuracy of multimorbidity and functional status as prognostic factors may vary over calendar time and between birth cohorts. The reason is that diagnostic criteria, treatments offered and the prevalence of multimorbidity and poor functional status have changed over time. Research clearly indicates that the incidence of chronic disease and the decline in functional status do change with later birth cohorts compared to earlier birth cohorts. ${ }^{36-38}$ An example is the incidence of myocardial infarction among younger people, which has steadily decreased over calendar time. ${ }^{36}$ The incidence of dementia in old age has declined over the last decades in both the USA and continental Europe. ${ }^{37,38}$ These downward trends cannot be explained by diagnostic bias or efforts over time or improved medical interventions. Most likely, better physical health and cognition among succeeding birth cohorts explain the temporal decline in dementia risk. ${ }^{39,40}$ In line with this interpretation, among the oldest old, the percentage of persons who can rise up from a chair markedly increased in recent birth cohorts. ${ }^{41}$

Regarding poor self-rated health, one study observed that over calendar time multimorbidity became less important while functional status became more important among people aged $60-85$ years. ${ }^{42}$ This indicates that also for self-reported measures of health, the importance of multimorbidity and functional level changes.

\section{Reflections}

The important issue is to recognize the tipping point, that is when does the prognostic value of the number of morbidities decrease and does the prognostic value of functional status become more important? Multimorbidity and functional status are clearly related in that most persons with functional limitations have multimorbidity, while only a minority of persons with multimorbidity has functional limitations. ${ }^{26}$ This imperfect correlation is agedependent. We suggest a gradual transition in which the focus on multimorbidity shifts to that of functional status.

An additional consideration is to focus on time points when persons change their expectations, eg widowhood or a move to a nursing home. Such changes may influence the prognostic value of multimorbidity or functional limitations.

A different approach would be to move the focus from chronological age to predicted remaining time until death. Research has shown that healthcare utilization, diagnoses, and drug use increase markedly in the last years of life. ${ }^{32}$ In this context, healthcare utilization is largely determined by the number of chronic diseases and less by attained age. ${ }^{43}$ It has been argued that in many clinical settings, it is possible to estimate time to death prospectively.

These reflections are important for the choice of measures used to assess prognosis. For younger persons, questionnaires or data from administrative registers, clinical databases, eHealth, or medical records could be used to identify multimorbidity, which has a high prognostic value in this age group. For the oldest old, multimorbidity, in terms of drug use and number of diagnoses, is not as predictive of health outcomes and such measures should be substituted by direct measurements of functional level. ${ }^{33}$ Functional level is often easy to measure by direct observation or by objective measures of physical capability. ${ }^{19}$ In summary, the point of this commentary is that this shift from number of diagnoses and multimorbidity to functional status is dependent on age, but also changes over calendar time and between birth cohorts.

\section{Ethics Statement}

This commentary does not include human or animal test subjects and is therefore exempted from requiring ethical approval. 


\section{Author Contributions}

All authors have made significant contributions to the commentary including writing and substantially revising the article. All authors have approved the version to be published and agree to be accountable for all aspects of the work.

\section{Disclosure}

The authors declare no conflicts of interest in this work.

\section{References}

1. Vaupel JW, Villavicencio F, Bergeron-Boucher MP. Demographic perspectives on the rise of longevity. Proc Natl Acad Sci U S A. 2021;118(9):e2019536118. doi:10.1073/pnas.2019536118

2. Partridge L, Deelen J, Slagboom PE. Facing up to the global challenges of ageing. Nature. 2018;561(7721):45-56. doi:10.1038/ s41586-018-0457-8

3. Fortin M, Soubhi H, Hudon C, Bayliss EA, Van den Akker M. Multimorbidity's many challenges. BMJ. 2007;334(7602):10 16-1017. doi:10.1136/bmj.39201.463819.2C

4. Navickas R, Petric VK, Feigl AB, Seychell M. Multimorbidity: what do we know? What should we do? J Comorb. 2016;6(1):4-11. doi:10.15256/joc.2016.6.72

5. Kaplan RM, Ong M. Rationale and public health implications of changing CHD risk factor definitions. Annu Rev Public Health. 2007;28:321-344. doi:10.1146/annurev.publhealth.28.021406.144141

6. Johnston MC, Crilly M, Black C, Prescott GJ, Mercer SW. Defining and measuring multimorbidity: a systematic review of systematic reviews. Eur J Public Health. 2019;29(1):182-189. doi:10.1093/eurpub/cky098

7. Nicholson K, Makovski TT, Griffith LE, Raina P, Stranges S, Van den Akker M. Multimorbidity and comorbidity revisited: refining the concepts for international health research. $J$ Clin Epidemiol. 2019;105:142-146. doi:10.1016/j.jclinepi.2018.09.008

8. Marengoni A, Angleman S, Melis R, et al. Aging with multimorbidity: a systematic review of the literature. Ageing Res Rev. 2011;10 (4):430-439. doi:10.1016/j.arr.2011.03.003

9. Alonso J, Ferrer M, Gandek B, et al. Health-related quality of life associated with chronic conditions in eight countries: results from the International Quality of Life Assessment (IQOLA) Project. Qual Life Res. 2004;13(2):283-298. doi:10.1023/B:QURE.0000018472.462 36.05

10. Valderas JM, Starfield B, Sibbald B, Salisbury C, Roland M. Defining comorbidity: implications for understanding health and health services. Ann Fam Med. 2009;7(4):357-363. doi:10.1370/afm.983

11. Smith SM, Soubhi H, Fortin M, Hudon C, O’Dowd T. Managing patients with multimorbidity: systematic review of interventions in primary care and community settings. BMJ. 2012;345:e5205. doi:10.1136/bmj.e5205

12. Ording AG, Sorensen HT. Concepts of comorbidities, multiple morbidities, complications, and their clinical epidemiologic analogs. Clin Epidemiol. 2013;5:199-203. doi:10.2147/CLEP.S45305

13. Vogeli C, Shields AE, Lee TA, et al. Multiple chronic conditions: prevalence, health consequences, and implications for quality, care management, and costs. J Gen Intern Med. 2007;22(Suppl 3):391-395. doi:10.1007/s11606-007-0322-1

14. Barnett K, Mercer SW, Norbury M, Watt G, Wyke S, Guthrie B. Epidemiology of multimorbidity and implications for health care, research, and medical education: a cross-sectional study. Lancet. 2012;380(9836):37-43. doi:10.1016/S0140-6736(12)60240-2
15. Schiotz ML, Stockmarr A, Host D, Glumer C, Frolich A. Social disparities in the prevalence of multimorbidity - A register-based population study. BMC Public Health. 2017;17(1):422. doi:10.1186/ s12889-017-4314-8

16. Quinones AR, Liang J, Bennett JM, Xu X, Ye W. How does the trajectory of multimorbidity vary across Black, White, and Mexican Americans in middle and old age? J Gerontol B Psychol Sci Soc Sci. 2011;66(6):739-749. doi:10.1093/geronb/gbr106

17. Canizares M, Hogg-Johnson S, Gignac MAM, Glazier RH, Badley EM. Increasing trajectories of multimorbidity over time: birth cohort differences and the role of changes in obesity and income. J Gerontol B Psychol Sci Soc Sci. 2018;73(7):1303-1314. doi:10.1093/geronb/gbx004

18. Fried LP, Tangen CM, Walston J, et al. Frailty in older adults: evidence for a phenotype. J Gerontol a Biol Sci Med Sci. 2001;56 (3):M146-M156. doi:10.1093/gerona/56.3.M146

19. Cooper R, Strand BH, Hardy R, Patel KV, Kuh D. Physical capability in mid-life and survival over 13 years of follow-up: British birth cohort study. BMJ. 2014;348:g2219. doi:10.1136/bmj.g2219

20. Kusumastuti S, Gerds TA, Lund R, Mortensen EL, Westendorp RGJ. Discrimination ability of comorbidity, frailty, and subjective health to predict mortality in community-dwelling older people: population based prospective cohort study. Eur J Intern Med. 2017;42:29-38. doi:10.1016/j.ejim.2017.05.016

21. Kusumastuti S, Rozing MP, Lund R, Mortensen EL, Westendorp RGJ. The added value of health indicators to mortality predictions in old age: a systematic review. Eur J Intern Med. 2018;57:7-18. doi:10.1016/j.ejim.2018.06.019

22. Kirkwood TB. Understanding the odd science of aging. Cell. 2005;120(4):437-447. doi:10.1016/j.cell.2005.01.027

23. Verbrugge LM, Jette AM. The disablement process. Soc Sci Med. 1994;38(1):1-14. doi:10.1016/0277-9536(94)90294-1

24. Clegg A, Young J, Iliffe S, Rikkert MO, Rockwood K. Frailty in elderly people. Lancet. 2013;381(9868):752-762. doi:10.1016/ S0140-6736(12)62167-9

25. Izaks GJ, Westendorp RG. Ill or just old? Towards a conceptual framework of the relation between ageing and disease. $B M C$ Geriatr. 2003;3:7. doi:10.1186/1471-2318-3-7

26. Vetrano DL, Palmer K, Marengoni A, et al. Frailty and multimorbidity: a systematic review and meta-analysis. J Gerontol A Biol Sci Med Sci. 2019;74(5):659-666. doi:10.1093/gerona/gly110

27. Nybo H, Petersen HC, Gaist D, et al. Predictors of mortality in 2,249 nonagenarians-the Danish 1905-Cohort Survey. J Am Geriatr Soc. 2003;51(10):1365-1373. doi:10.1046/j.1532-5415.2003.51453.x

28. Schneeweiss S, Maclure M. Use of comorbidity scores for control of confounding in studies using administrative databases. Int J Epidemiol. 2000;29(5):891-898. doi:10.1093/ije/29.5.891

29. Yurkovich M, Avina-Zubieta JA, Thomas J, Gorenchtein M, Lacaille D. A systematic review identifies valid comorbidity indices derived from administrative health data. J Clin Epidemiol. 2015;68 (1):3-14. doi:10.1016/j.jclinepi.2014.09.010

30. Skajaa N, Ording AG, Darvalics B, Horvath-Puho E, Sorensen HT. Long-term mortality in young and middle-aged adults hospitalised with chronic disease: a Danish cohort study. BMJ Open. 2020;10(10): e038131. doi:10.1136/bmjopen-2020-038131

31. Gils C, Christensen K, Nybo M. A population-based study of cholesterol measurements in the oldest old. Curr Aging Sci. 2015;8 (3):282-287. doi:10.2174/1874609808666150902093136

32. Pedersen JK, Jensen TM, Waldorff FB, Sondergaard J, Christensen K. Use of prescription medication in the last years of life: a population-based comparison of two oldest old Danish birth cohorts born 10 years apart. Age Ageing. 2020;49(6):1105-1109. doi:10.1093/ageing/afaa064

33. Thinggaard M, McGue M, Jeune B, Osler M, Vaupel JW, Christensen K. Survival prognosis in very old adults. J Am Geriatr Soc. 2016;64(1):81-88. doi:10.1111/jgs.13838 
34. Buccheri G, Ferrigno D, Tamburini M. Karnofsky and ECOG performance status scoring in lung cancer: a prospective, longitudinal study of 536 patients from a single institution. Eur $J$ Cancer. 1996;32A(7):1135-1141. doi:10.1016/0959-8049(95)006 64-8

35. Straatmann VS, Vetrano DL, Fratiglioni L, Calderon-Larranaga A. Disease or function? What matters most for self-rated health in older people depends on age. Aging Clin Exp Res. 2020;32(8):1591-1594. doi:10.1007/s40520-020-01507-1

36. Degano IR, Salomaa V, Veronesi G, et al. Twenty-five-year trends in myocardial infarction attack and mortality rates, and case-fatality, in six European populations. Heart. 2015;101(17):1413-1421. doi:10.11 36/heartjnl-2014-307310

37. Wu YT, Beiser AS, Breteler MMB, et al. The changing prevalence and incidence of dementia over time - current evidence. Nat Rev Neurol. 2017;13(6):327-339. doi:10.1038/nrneurol.2017.63

38. Taudorf L, Norgaard A, Islamoska S, Jorgensen K, Laursen TM, Waldemar G. Declining incidence of dementia: a national registry-based study over 20 years. Alzheimers Dement. 2019;15 (11):1383-1391. doi:10.1016/j.jalz.2019.07.006
39. Livingston G, Huntley J, Sommerlad A, et al. Dementia prevention, intervention, and care: 2020 report of the Lancet Commission. Lancet. 2020;396(10248):413-446.

40. Wolters FJ, Chibnik LB, Waziry R, et al. Twenty-seven-year time trends in dementia incidence in Europe and the United States: the Alzheimer Cohorts Consortium. Neurology. 2020;95(5):e519-e531. doi:10.1212/WNL.0000000000010022

41. Christensen K, Thinggaard M, Oksuzyan A, et al. Physical and cognitive functioning of people older than 90 years: a comparison of two Danish cohorts born 10 years apart. Lancet. 2013;382 (9903):1507-1513. doi:10.1016/S0140-6736(13)60777-1

42. Galenkamp H, Braam AW, Huisman M, Deeg DJ. Seventeen-year time trend in poor self-rated health in older adults: changing contributions of chronic diseases and disability. Eur J Public Health. 2013;23(3):511-517. doi:10.1093/eurpub/cks031

43. Hansen AV, Mortensen LH, Trompet S, Westendorp R. Health care expenditure in the last five years of life is driven by morbidity, not age: a national study of spending trajectories in Danish decedents over age 65. PLoS One. 2020;15(12):e0244061. doi:10.1371/journal.pone.0244061
Clinical Epidemiology

\section{Publish your work in this journal}

Clinical Epidemiology is an international, peer-reviewed, open access, online journal focusing on disease and drug epidemiology, identification of risk factors and screening procedures to develop optimal preventative initiatives and programs. Specific topics include: diagnosis, prognosis, treatment, screening, prevention, risk factor modification,

Submit your manuscript here: https://www.dovepress.com/clinical-epidemiology-journal systematic reviews, risk \& safety of medical interventions, epidemiology \& biostatistical methods, and evaluation of guidelines, translational medicine, health policies \& economic evaluations. The manuscript management system is completely online and includes a very quick and fair peer-review system, which is all easy to use. 